\title{
THE ROLE OF ONLINE EDUCATION PREFERENCES ON STUDENT'S ACHIEVEMENT
}

\author{
Assoc. Prof. Dr. Meltem Huri BATURAY \\ Distance Learning Research \& Implementation Center \\ Ipek University, Ankara, TURKEY \\ Assoc. Prof. Dr. Erman YUKSELTURK \\ Department of Computer Education \\ and Instructional Technology \\ Faculty of Education, Kırıkkale University, \\ Kırıkkale, TURKEY
}

\begin{abstract}
Online education has expanded and is expected to continue growing rapidly in time along with technological innovations. It is obvious that there is a movement toward online learning which necessitates the need of more empirical evidence on effective learning and learners' achievement. This study investigated effect of the variables: demographics (age, gender, being employed/unemployed, and computer efficacy); Internet self-efficacy; satisfaction (student-student, student-instructor, student-content interaction); and the reasons for online education preferences of students' on their achievement. Differing from previous studies the current study particularly investigates the effect of students' reasons for their preferences of distance education on their success besides all other variables. The results indicated that there is a positive correlation between students' reasons for their preferences of distance education and their achievement scores which was measured by their final test scores. Besides, according to results of the regression analyses, preferences related to achievement was the only variable to affect regression equation in the online course regression analyses. That was accounted for about $\mathbf{5 . 1} \%$ of the variance in students' final grades.
\end{abstract}

Keywords: Online learning; distance education; preference; achievement; satisfaction; demographics; Internet self-efficacy.

\section{THE ROLE OF ONLINE EDUCATION PREFERENCES ON STUDENT'S ACHIEVEMENT}

It is not as easy to inspect the differences in student learning in online settings as in traditional ones. There is a broad range of constructs as proven predictors of academic achievement in online learning environments (OLEs). And these constructs or factors have been classified differently by different researchers (Blocher, Montes, Willis \& Tucker, 2002; Ergul, 2004; Lim, Morris \& Yoon, 2006; Schrum \& Hong, 2002; Yukselturk \& Bulut, 2007). For example, Schrum and Hong (2002) identified and confirmed seven dimensions significant for successful online learners which were; access to tools, technology experience, learning preferences, study habits and skills, goals or purposes, lifestyle factors, personal traits and characteristics.

Demographics such as gender, age, being employed or unemployed, learners' Internet or computer self-efficacy, their characteristics and learning styles etc. are some other constructs to affect students' achievement in OLEs. Online learners are expected to have 
a certain level of technical skills, prior computer experience and knowledge to successfully engage in online learning (Lim \& Kim, 2003; Wojciechowski \& Palmer, 2005).

If this does not happen, provision of a pre-course orientation for first-time virtual students is important as suggested by Roblyer, Davis, Mills, Marshall, \& Pape (2008). In fact, this should be a requirement in all virtual schools. Regarding instructional characteristic and learners' cognitive style, Güngör and A kar (2004) found fieldindependent learners to be more successful than field-dependent learners on their study investigating the effects of e-learning and cognitive style on achievement and perceived Internet self-efficacy.

Online learners' ability to self-regulate, self-monitor their learning and resources, selfawareness of motivation and cognitive/metacognitive strategies are vital due to the isolated learning environment (Blocher, Montes, Willis \& Tucker, 2002). Self-regulation is defined as "self-generated thoughts, feelings, and actions that are planned and cyclically adapted to the attainment of personal goals" (Zimmerman, 2000, p. 14). Grabinger and Dunlop (2000) claimed OLEs require self-directed learning affording greater opportunities for individualization and flexibility. To Ergul (2004), high motivation, maturity and self-discipline are general characteristics of successful learners in distance education programs and self-efficacy of distance education was found significantly correlated to students' academic achievement. Similarly, in her study, Lim (2001) indicated self-efficacy in computer knowledge to be the only significant variable predicting achievement.

It is obvious that there is a strong cause and effect relationship between motivation and achievement. Lim and Kim (2003) grouped online learning motivation variables as:

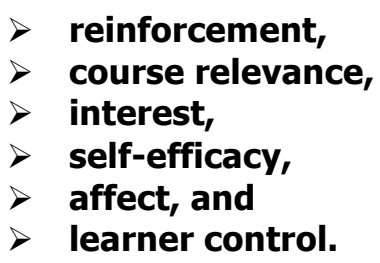

The motives of learners could as well be categorized as intrinsic and extrinsic ones. To Mandernach, Donnelli and Dailey-Hebert (2006) external factors: time, technology, initiative and competence emerge as the most predictive of learner success. According to the results of Song, Singleton, Hill and Koh's study (2004) most learners agreed that course design, learner motivation, time management, and comfortableness with online technologies impact the success of an online learning experience. Particularly, students' levels of intrinsic and extrinsic motivation seem to be a more accurate predictor of student success and persistence (Shih \& Gamon, 2001).

Interaction is claimed to be one of the other most important elements of online learning (Moore, 2001). It appears that to benefit from interaction-related tools of e-learning classrooms positively influence the achievement and satisfaction of learners (Bouhnik \& Marcus, 2006). Online or e-learning implies a technology-mediated interactive learning environment through which collaboration and group interaction is actively supported for educational practice (Blocher, Montes, Willis \& Tucker, 2002). Study groups and contacts with the instructor were reported to be positively contributing to learners' success (King, Harner, \& Brown, 2000).

This study aims to investigate affect of the variables: demographics (the age, gender, employed/unemployed, computer knowledge); Internet self-efficacy; interaction (student-student, student-instructor, student-content); and the reasons for online education preference of students' on their achievement. Differing from previous online students' achievement studies, this study particularly focuses on the effect of online 
education preferences of students on their achievement. Thus, the study tries to find answer to the following major research question:

$>$ What is the extent to which selected variables (gender, age, employed/unemployed, computer knowledge, Internet self-efficacy, reasons of preferences, student-student and student-content, studentinstructor interaction) could account for students' achievement in an online course?

\section{METHOD}

This study examined the relationship between various student characteristics and achievement in an online course. It adopted correlational research design which was used for the explanation of important human behaviours and for the exploration of relationships between variables (Fraenkel \& Wallen, 2000). Thus, the data was quantitatively collected for the analysis.

\section{Subject of the Study}

This study included the students who were enrolled in an online elementary-level English language course taught entirely through a Learning Management System. In this study the researchers utilized the convenience sampling. According to Fraenkel and Wallen (2000), the sample that is easy accessible is convenience sample.

Originally, 450 students attended to the course; however, this study included the ones who were volunteers to participate in the study $(\mathrm{N}=148)$. The number of male participants $(N=95)$ was greater than the number of female participants $(N=53)$, and the participants' age ranged from 18 to 35 . The majority of the participants' ages were between 18 and $25(76 \%)$. Besides, nearly half of the students had a part-time or fulltime job (48 \%).

\section{Description of the Online English Language Course}

The online English language course was entirely given via the Internet through a Learning Management System (LMS) that consisted of the following set of tools:

$>$ content management tools that allowed the course instructor to present multimedia content, supplementary course materials, and course weekly schedule;

$>$ assessment tools such as online test/exam preparation, online testing and test/exam question pool;

> student tools such as student lists, students' reports and student grade book;

$>$ communication and collaboration tools, that consisted of e-mail, net meeting, announcements, discussion boards and an agenda to take personal notes.

The English language course content included sections on vocabulary, grammar, reading and writing, listening, and speaking. The grammar was supported with video recorded tutoring in which the instructor taught grammatical structures in the students' native language, Turkish.

The instructor met with the students through weekly meetings which were implemented through text-based chats. Students had the opportunity to ask questions at real-time about issues that hadn't been understood well. After answering all questions of the students and reviewing incomprehensible issues together with her students, the instructor conducted a language drill and practice activity in each weekly session.. Students could interact with their peers asynchronously using the text-based discussion board, as well. The instructor monitored all students' postings (Author, 2010). 
$>$ To collect relevant data, the following instruments were used: Ademographics Survey, Distance Education Preferences Survey, An Internet Self-efficacy Scale and The Course Evaluation Survey (CES).

$>$ The Demographics Survey: It included items that addressed the students' age, gender, employed/unemployed (their current situation of being employed/unemployed), and computer efficacy level.

> Distance Education Preferences Survey: Adapted from Qureshi, Morton \& Antosz (2002), the survey was used to measure the reasons for students' preferences of online education mode instead of on-campus mode. The answer 'very true' received a score of 5 and the answer 'not true at all' a score of 1 . The scale included 14 items such as "Transportation difficulties made it difficult for me to get to the campus (e.g., poor bus service, or lack of parking, etc.)", "I don't want to go to school full-time", "My physical disabilities made it difficult for me to attend on-campus courses".

$>$ Internet Self-efficacy Scale: Adapted from Joo, Bong and Choi (2000), this scale was used to determine the perceived capability of students to use the Internet. The scale had a high internal consistency as demonstrated by the Cronbach's of .95. There was a five-point Likert-type scale of potential responses: Very true, mostly true, somewhat true, mostly not true, and not true at all, with assigned values between 5 and 1 . The answer 'very true' received a score of 5 and the answer 'not true at all' a score of 1 . The scale included 13 items and was administered shortly after the semester began. The scale was piloted for Turkish online students and Cronbach's coefficient alpha of .90 was found for the scale (Author \& Bay, 2010).

$>$ The Course Evaluation Survey: The Course Evaluation Survey was used to evaluate students' perceptions of satisfaction with the online course. It was prepared and administered using Web Builder developed by North Carolina State University's College of Agriculture and Life Sciences (CALS) to be administered to students enrolled in university courses (Lucas, 2007). It consists of 3 sub-parts for evaluating learner-to-learner, learner-tocontent and learner-to-instructor interaction within the course with 31 items in total. Cronbach's coefficient alpha was .94 for the learner-tolearner interaction subscale, .90 for the learner-to-content interaction, and .96 for learner-to-instructor interaction. There was a five-point Likert-type scale of potential responses: strongly agree, somewhat agree, agree, somewhat disagree, and strongly disagree. The assigned values for each item ranged between 5 and 1, with 5 for the answer "strongly agree" and the value 1 for the answer "strongly disagree". The course evaluation survey was piloted and Cronbach Alpha was measured .92 (Author, 2010).

$>$ Achievement Test: It was a teacher-produced proctored test that consisted of 25 multiple choice questions and measured students' learning. Each correctly answered question is scored as 4 points with 100 possible points. The test was taken face-to-face by the online students at the end of the semester.

\section{Data Collection and Analysis}

Data was collected in the 2008-2009 fall semester from the students who attended Online English Language Course in a distance education program at a higher education institution in Turkey. Data was collected through several online questionnaires. Data regarding demographics, reasons for online education preferences and internet self-efficacy of students were collected at the beginning; whereas, course evaluation (satisfaction) with achievement scores were collected at the end of the semester. Based on collected data, nine independent variables (four categorical: gender, age, being employed/unemployed, computer efficacy level and five continuous: Internet self-efficacy, reasons for students' preferences of online education, student-student interaction, student-content interaction, student-instructor interaction) were extracted. The dependent variable, students' final test scores, was extracted 
based on the achievement test (instructor-produced proctored test) at the end of the course. Descriptive and inferential statistics were used to analyze the quantitative data. At the descriptive level, simple means and frequency distributions were employed.

At the inferential level, Pearson product-moment correlation coefficients (Pearson $r$ ) were used to determine any statistically significant relationships $(p=<.01)$ between each selected independent variable and the student final test grade obtained in the online course. A regression analysis was performed to obtain an estimate of the percentage of variance within the final test grade a student received as accounted for by the various independent variables.

\section{RESULTS}

\section{Descriptive Statistics}

Table 1 shows the descriptive statistics (range, $\min$, max, mean, standard deviation) of the variables, Internet self-efficacy (self-efficacy), reasons for students' preferences of online education, (preferences), interactions (student-student, student-content, student-instructor) and achievement scores. As indicated in Table 1, students had quite high perceived Internet selfefficacy (mean $=59.7$ out of 65 ) and students' preferences of online education were generally low (mean $=29.6$ out of 70). Also, most students thought that they interacted with other students (mean $=36.1$ out of 50$)$, content (mean $=39.8$ out of 50$)$ and teacher (mean $=44.6$ out of 55).

Table: 1

Descriptive Statistics of Independent Variables

\begin{tabular}{ccccccc}
\hline Predictors & N & Range & Min & Max & Mean & Std. \\
\hline self-efficacy & 148 & 41 & 24 & 65 & 59.7 & 6.1 \\
preferences & 148 & 36 & 14 & 50 & 29.6 & 8.1 \\
s-s interaction & 148 & 35 & 15 & 50 & 36.1 & 7.9 \\
s-c interaction & 148 & 36 & 19 & 55 & 39.8 & 7.2 \\
s-t interaction & 148 & 40 & 10 & 50 & 44.6 & 6.3 \\
final grade & 148 & 88 & 8 & 96 & 50.1 & 19.3 \\
\hline
\end{tabular}

\section{Correlation and Regression Analysis}

The Pearson $r$ was the correlation index that used to measure the degree of relationship between nine independent variables and the dependent variable of student achievement in the online course.

Table: 2.

Pearson Product-Moment Correlations among Measures for All Subjects of the Study

\begin{tabular}{llllllllll}
\hline Variables & 2 & 3 & 4 & 5 & 6 & 7 & 8 & 9 & 10 \\
\hline 1.Gender & 0.49 & 0.13 & $0.26 *$ & 0.01 & $0.30 *$ & -0.08 & 0.13 & -0.02 & 0.08 \\
2.Age & & $0.29 *$ & -0.09 & 0.15 & 0.20 & 0.07 & 0.10 & 0.09 & 0.2 \\
3.Employment & & & 0.04 & 0.08 & 0.17 & 0.04 & 0.07 & 0.01 & -0.10 \\
4. Comp. know & & & & 0.07 & 0.14 & 0.16 & 0.04 & 0.02 & 0.14 \\
5. Self-effica. & & & & & -.0 .02 & 0.05 & 0.02 & 0.04 & 0.11 \\
6.Preferences & & & & & & 0.05 & 0.33 & 0.03 & $0.23 *$ \\
7.s-s interact. & & & & & & & 0.10 & 0.11 & -0.05 \\
8.s-c interact. & & & & & & & & $0.5 *$ & 0.01 \\
9.s-t interact. & & & & & & & & & 0.04 \\
10. Final grade & & & & & & & & & 1
\end{tabular}


Table: 2 summaries the correlation results, and whether they are significant or not (at the $p=<0.01$ level). Results indicate that a statistically significant relationship exists between student's final test scores and reasons for their preferences of online education.

In addition, a linear regression analysis was performed to estimate the percentage of variance accounted for the final test grade a student receives, using various independent variables. The goal of regression analysis was to create a predicting equation that was close to reality without using more variables than necessary to make an accurate prediction of student achievement. According to the results, only one variable (preferences) explained a significant amount of variance in students' achievement, $R^{2}=0.051$, adjusted $R^{2}=0.044, F(1,147)=7.844, p=0.006$. 5.1 percent of the variances are explained by this variable. The other variables were excluded from the equation of predicting students' achievement because they did not have a significant contribution to variance in their final test grades.

\section{DISCUSSION}

There exist a great number of studies investigating the factors that contribute to achievement of online learners in the literature. These factors might be gathered under the following categorization:

$>$ demographic characteristics, such as, age, gender, and employment;

$>$ individual characteristics, such as, preferences, technical skills, and needs;

$>$ self-regulated learning strategies, such as, self-efficacy, self-regulation, self-awareness;

$>$ motivation, such as, intrinsic and extrinsic goal orientation, locus of control

$>$ interaction, such as, student-student, student-content, student-teacher; (Blocher, Montes, Willis \& Tucker, 2002; Ergul, 2004; Schrum \& Hong, 2002; Wojciechowski \& Palmer, 2005; Yukselturk \& Bulut, 2007).

It is well-known that online learners are expected to behave different from traditional learners in order to be successful in the OLEs since OLEs do not correspond with traditional face-to-face learning environments with the facilities they provide and the requirements they entail, and they often ascribe an extra burden on the learners. Thus, there is much more research needed that investigates the needs and characteristics of online learners and the factors leading them to success. In the current study, the researchers examined various student characteristics and their relationship to achievement in an online course. For this aim, the effect of nine learner characteristics on students' achievement was investigated in the online course. These characteristics were: gender, age, employment, computer efficacy level, Internet self-efficacy, reasons for their preferences of online education, student-student, student-content, studentinstructor interactions. The results indicated that there is a positive correlation between students' reasons for their preferences of online education and their achievement which was measured by their final test scores. Besides, according to results of the regression analyses, preferences related to achievement was the only variable to affect regression equation in the online course regression analyses. That was accounted for about $5.1 \%$ of the variance in students' final grades.

Rovai, Ponton, Wighting and Baker (2007) stated the advantages of online learning as ease of access, flexibility in teaching and learning approaches with enhanced educational opportunities for students. Time constraints, travel costs, and conflicting work schedules of face-to-face learning are often cited as reasons for engaging in online courses. Some of the other advantages of online learning are stated as individualized instruction, use of interactive learning materials (Gratton-Lavoie \& Stanley, 2009), convenience or flexibility at which one can study and a more student centered way of learning (Broadley \& Trinadad, 2008; Murray, Casey \& Fraser, 2007). 
These advantages are stated to have a significant impact on students' preferences for online learning. Similar to previous findings regarding advantages of online mode of learning compared to face-to-face mode, this study indicates that the reasons for students' preference of online learning might highly affect their achievement. That is, the students who preferred online education based on some of the advantages were found to be more successful than others. Therefore, the students who are more eager and determined to participate in an online learning experience taking account of some of its advantages are expected to be more successful.

Thus, it is supposed that when online learners start an online course, they first ensure whether the course or program meets their expectations, which are likely to affect their success. If students' expectations are not met, they probably will not be successful at the end or will probably dropout from the online course/program. Regarding this, Chyung (2001) suggested tracking of online learners which refers to the fact that initial active involvement of students in online courses predicts their success. It is stated that students who are active in the first few weeks of the class are more likely to be successful in the course and dropout behaviour is most likely to occur in the early weeks of the course (Chyung 2001). This finding might be related to the fact that after students have experienced that their expectations are not met, they are likely to dropout the course. Similarly, Wang and Newlin (2002) suggest online instructors that they should consider the reasons why students enroll in their classes and they should closely monitor the on-line, course- related activity of their students. To them students' early behaviors are correlated with their final grades.

\section{CONCLUSION}

It is known that all students could not be successful in an educational environment, particularly, when it is in an online environment. They could not accomplish the course requirements and finally they fail the course just because of their expectations are not met. Meeting learners' expectations such as provision of a flexible and individualized, interactive, user-friendly, easily accessible and an effective learning environment is important for their success.

Any organization willing to increase the number of enrollments in and qualification of its online courses or programs should build up \& sustain learners' satisfaction and yield successful graduates. Similarly, any designer willing to design a qualified and effective online course should, therefore, give priority to meeting learners' preferences, expectations and needs.

The current study might be useful in identifying characteristics of successful and highrisk students in online education and contribute to the drop-out studies. It is believed that high quality online learning environments can be designed through early interventions.

As a recommendation for further studies, examining more than one group of students is recommended. Online students' preferences might change according to their age group, the aim of the course they have registered etc.

Therefore, verification of the current study's results with some other sample might be worthy of consideration in future studies. In addition, the views of university administrators, instructors of online courses, course designers might be assessed to determine all factors that affect achievement of students and to evaluate student performance from several aspects.

For the generalizability of the findings, the sample size might be increased. Also, a longitudinal study might reveal the hidden factors for students' success in the long term. 


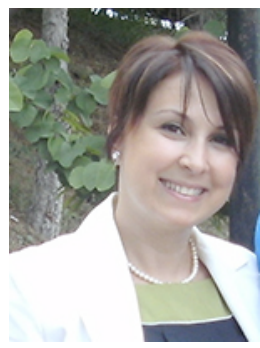

Dr. Meltem Huri BATURAY is an instructor at the Department of Animation at Ipek University in Ankara, Turkey. She is the director and founder of Distance Learning Research and Implementation Center at the same university. She received her doctorate degree (2007) in Computer Education and Instructional Technology from Middle East Technical University. Dr. Baturay's areas of professional interest include e-learning, MOOCs, online social learning environments and web-based foreign language teaching.

Assoc. Prof. Dr. Meltem Huri BATURAY

Distance Learning Research \& Implementation Center

Ipek University, Ankara, TURKEY

Phone: +9031247041 16

T: $+903124700000 / 4611$

F: + 903124700007

Mobile GSM: +90 5548381381

Skype: meltem.baturay

Email: mbaturay@ipek.edu.tr

URL: http://www.ipek.edu.tr

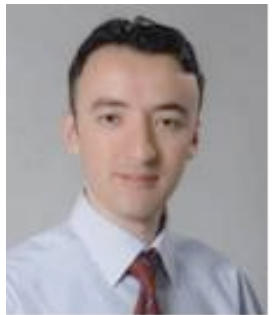

Dr. Erman YUKSELTURK completed his MS (2003) and PhD (2007) in the Department of Computer Education and Instructional Technology at the Middle East Technical University (METU) in Turkey. Associate. Prof. Dr. Erman Yükseltürk currently works at the Department of Computer Education and Instructional Technology in Kırıkkale University, Kırıkkale, Turkey. His research focuses on mainly design, development and implementation of online learning environment. Also, his research interests include teacher education; instructional technology and integration of technology into various learning environments; team based learning; Web 2.0 technologies; and related assessment and evaluation processes.

Assoc. Prof. Dr. Erman YUKSELTURK

Department of Computer Education and Instructional Technology

Faculty of Education, Kırıkkale University, Kırıkkale, TURKEY

Phone: +90 3122103547

MobileGSM: +905056815124

Skype: ermanyukselturk

Email: eyukselturk@gmail.com

\section{REFERENCES}

Baturay, M. H. (2010). Relationships among Sense of Classroom Community, Perceived Cognitive Learning and Satisfaction of Students at an E-learning Course. Interactive Learning Environments, 19(5), 563-575.

Baturay, M. H. \& Bay, O. F. (2010). The Effects of Problem-Based Learning on the Classroom Community Perceptions and Achievement of Web-based Education Students. Computers \& Education, 55, 43-52.

Blocher, J. M., Montes, L. S., Willis, E.M. \& Tucker, G. (2002). Online learning: Examining the successful student profile. The Journal of Interactive Online Learning, 1(2): 1-12.

Bouhnik, D., \& Marcus, T. (2006). Interaction in distance-learning courses. Journal of the American Society for Information Science and Technology, 57 (3), 299-305. 
Broadley, T., \& Trinidad, S. (2008). Teachers working in an online world. In N.Yelland, G. Neal \& E. Dakich (Eds.)., Rethinking education with ICT: New directions for effective practices, (pp.149-164). Rotterdam, The Netherlands: Sense Publishers.

Chyung, S. (2001). Systematic and systemic approaches to reducing attrition rates in online higher education. The American Journal of Distance Education 15 (3): 36-49.

Ergul, H. (2004). Relationship between student characteristics and academic achievement in distance education and application on students of Anadolu University. Turkish Online Journal of Distance Education 5(2).

Grabinger, R.S. \& Dunlap, J.C. (2000). Rich environments for active learning: A definition. In Squires, D., Conole, G. \& Jacobs, G. (Eds.). The changing face of learning technology (pp.8-38). Cardiff, Wales, UK, University of Wales.

Gratton-Lavoie, C. \& Stanley, D. (2009). Teaching and Learning Principles of Micro economics Online: An Empirical Assessment. Journal of Economic Education, 40(1), 3-25.

Güngör, C. \& A kar, P. (2004). E-ö renmenin ve bili sel stilin ba arı ve internet özyeterlik algızı üzerindeki etkisi. H.Ü. E itim Fakültesi Dergisi, 27, 116-125.

Joo, Y., J., Bong, M., \& Choi, H. J. (2000). Self-efficacy for self-regulated learning, academic selfefficacy, and Internet self-efficacy in Web-based instruction. Educational Technology Research and Development, 48(2), 5-17.

King, B. F., Harner, M., \& Brown, W. C. (2000). Self-regulatory behavior influences in distance learning. International Journal of Instructional Media, 27 (2), 147-156.

Lim, C. K. (2001). Computer self-efficacy, academic self-concept, and other predictor of satisfaction and future participation of adult distance learners. The American Journal of Distance Education. 15(2), 41-51.

Lim, D. H., \& Kim, H. J. (2003). Motivation and learner characteristics affecting online learning and learning application. Journal of Educational Technology Systems, 31 (4), 423-439.

Lim, D. H., \& Morris, M. L. (2009). Learner and Instructional Factors Influencing Learning Outcomes within a Blended Learning Environment. Educational Technology \& Society, 12 (4), 282-293.

Lim, D. H., Morris, M. L. \& Yoon, S. W., (2006). Combined effect of instructional and learner variables on course outcomes within an online learning environment. Journal of Interactive Online Learning, 5(3), 255-269.

Lucas, J. W. (2007). Personality Type (MBTI) Relationship to performance and satisfaction in web-based instruction (WBI). A dissertation, Graduate Faculty of North Carolina State University, US.

Mandernach, B. J., Donnelli, E. \& Hebert-Dailey, A. (2006). Learner attribute research juxtaposed with classroom practice: Predictors of success in the accelerated, online classroom. Journal of Educators Online, 3 (2).

Moore, M.G. (2001). Surviving as a distance teacher. American Journal of Distance Education, 15(2), 1-5. 
Murray D., Casey, D., \& Fraser, J. (2007). Talkabout Walkabout: Evaluation of a Flexible Learning Initiative. In P. Tsang., R. Kwan., \& R. Fox (Eds.), Enhancing Learning through Technology. World Scientific Publishing Co: Singapore.

Qureshi, E., Morton, L. L. \& Antosz, E. (2002). An interesting profile-university students who take distance education courses show weaker motivation than on-campus students. Online Journal of Distance Learning Administration, 5(4).

Roblyer, M. D., Davis, L., Mills, S., Marshall, J., \& Pape, L. (2008). Toward practical procedures for predicting and promoting success in virtual school students. The American Journal of Distance Education, 22(2), 90-109.

Sankaran, S., \& Bui, T. (2001). Impact of learning strategies and motivation on performance: A study in Web-based instruction. Journal of Instructional Psychology, 28(3), 191-198.

Schrum, L. \& Hong, S. (2002). From the field: characteristics of successful tertiary online students and strategies of experienced online educators. Education and Information Technologies 7(1), 5-16.

Shih, C. C. \& Gamon, J. (2001). Web-based learning: Relationships among student motivation, attitude, learning styles, and achievement. Journal of Agricultural Education, 2(4), 12-20.

Song, L., Singleton, E. S., Hill, J. R., \& Koh, M. H. (2004). Improving online learning: Student perceptions of useful and challenging characteristics. Internet and Higher Education, 7, 59-70.

Wojciechowski, A. \& Palmer, L.B (2005) Individual student characteristics: can any be predictors of success in online classes? Online Journal of Distance Learning Education, 8(2).

Wang, A. Y. \& Newlin, M. H. (2002). Predictors of web student performance: the role of self-efficacy and reasons for taking an on-line class. Computers in Human Behavior, 18(2), 151-163.

Yukselturk, E. \& Bulut S. (2007) Predictors for Student Success in an Online Course, Educational Technology \& Society,10(2), 71-83.

Zimmerman, B. J. (2000). Attaining self-regulation: A social cognitive perspective. In M. Boekaerts, P. R. Pintrich, \& M. Zeidner (Eds.), Handbook of self-regulation (pp. 13-39). New York: Academic Press. 